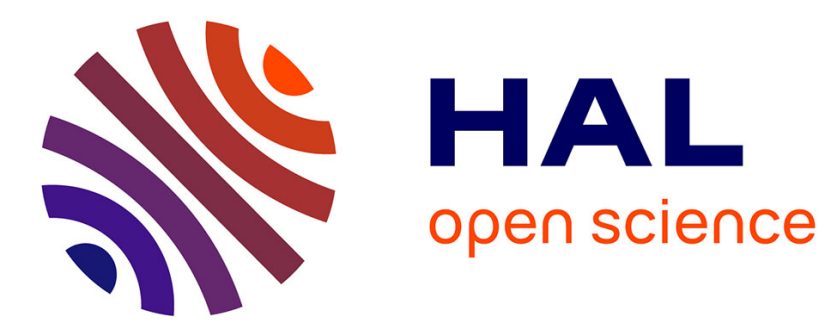

\title{
Glass forming tendency in Ga-Ge-S glasses : a structural approach
}

\author{
N. Chbani, A. Loireau-Lozac'H, F. Keller, S. Bénazeth
}

\section{To cite this version:}

N. Chbani, A. Loireau-Lozac'H, F. Keller, S. Bénazeth. Glass forming tendency in Ga-Ge-S glasses : a structural approach. Journal de Physique IV Proceedings, 1994, 04 (C9), pp.C9-113-C9-116. 10.1051/jp4:1994915 . jpa-00253475

\section{HAL Id: jpa-00253475 https://hal.science/jpa-00253475}

Submitted on 1 Jan 1994

HAL is a multi-disciplinary open access archive for the deposit and dissemination of scientific research documents, whether they are published or not. The documents may come from teaching and research institutions in France or abroad, or from public or private research centers.
L'archive ouverte pluridisciplinaire HAL, est destinée au dépôt et à la diffusion de documents scientifiques de niveau recherche, publiés ou non, émanant des établissements d'enseignement et de recherche français ou étrangers, des laboratoires publics ou privés. 


\title{
Glass forming tendency in Ga-Ge-S glasses: a structural approach
}

\author{
N. Chbani, A.M. Loireau-Lozac'h, F. Keller* and S. Bénazeth**,*** \\ Laboratoire de Chimie Physique Générale et Minérale, Faculté de Pharmacie, Université Paris V, 4 Avenue \\ de l'Observatoire, 75270 Paris, France \\ * Laboratoire de Biomathématiques et Physique, Faculté de Pharmacie, Université Paris V, 4 Avenue de \\ l'Observatoire, 75270 Paris, France \\ ** Laboratoire LURE, Université Paris-Sud, 91405 Orsay, France \\ *** Laboratoire de Chimie Physique Minérale et Bioinorganique, Faculté de Pharmacie, Université \\ Paris-Sud, 92296 Chatenay-Malabry, France
}

\begin{abstract}
:
We have studied by EXAFS glasses that belong to the $\mathrm{Ga}_{2} \mathrm{~S}_{3}-\mathrm{GeS}_{2}$ line around $\mathrm{Ga}$ and $\mathrm{Ge} \mathrm{K}$ edges. Both tetrahedral GaS4 and GeS4 units are evidenced and low temperature measurements reveal ordering around germanium atoms up to $4 \AA$.
\end{abstract}

\section{INTRODUCTION}

Besides semiconducting chalcogenide glasses based on well known former elements as for instance germanium or arsenic, it exits a wide class of chalcogenide gallium based glasses which are not so often described. These glasses present a peculiar behaviour related to the impossibility to obtain bulk $\mathrm{Ga}-\mathrm{S}$ or $\mathrm{Ga}-$ Se binary glasses by using conventional quenching. The glassy state is therefore reached by synthesis of more complex materials which contain either modifier elements ( rare earth elements for instance) or some former elements (germanium for instance). These materials then support thermal and physical properties which are interesting for many applications (1-5). Some structural studies have been developped about these glasses (3) but they provided no explanation why binary sulfide gallium glasses do not exist and leave open the question of the low glass forming ability of gallium. One approach of this problem we present here is to study mixed gallium and germanium sulfide glasses in order to compare local and medium range order (if exists) around gallium and germanium atoms. We choose to work along the quasi-binary system $\mathrm{Ga}_{2} \mathrm{~S}_{3}-$ $\mathrm{GeS}_{2}$ for which glasses are prepared in a wide extent on $\mathrm{GeS}_{2}$ side. The structural technique we have used is the Extended-Xray-Absorption-Fine-Structure well suited to investigate separately $\mathrm{Ga}$ and $\mathrm{Ge}$ surroundings.

\section{EXPERIMENTS}

All the bulk samples have been prepared from the $\mathrm{Ga}_{2} \mathrm{~S}_{3}-\mathrm{GeS}_{2}$ sulfides mixed according to convenient proportions. The mixtures were melt in silica ampoules at $1373 \mathrm{~K}$ and then quenched in cold water. $X$-ray diffraction diagrams were registered to prove glassy state. We did thus prepare:

$$
\begin{aligned}
& \text { sample (1) } 9 \mathrm{GeS}_{2}-0.5 \mathrm{Ga}_{2} \mathrm{~S}_{3} \\
& \text { sample (2) } 7 \mathrm{GeS}_{2}-1.5 \mathrm{Ga}_{2} \mathrm{~S}_{3} \\
& \text { sample (3) } 3 \mathrm{GeS}_{2}-1 \mathrm{Ga}_{2} \mathrm{~S}_{3}
\end{aligned}
$$

X-ray absorption spectroscopy measurements were carried out on the EXAFS II station at the DCI storage ring of LURE (Orsay) at the $\mathrm{Ga}(10367 \mathrm{eV})$ and $\mathrm{Ge}(11104 \mathrm{eV}) \mathrm{K}$ edges. We used transmission mode measurements at room temperature and $7 \mathrm{~K}$ by using a helium liquid cryostat. Energy selection was made using a Si (311) double crystal monochromator. Considering the relatively high energy of the $\mathrm{K}$ edges studied no rejection harmonic mirrors were used. The EXAFS analytical procedure has been fully described elsewhere (6) and we used single scattering theory and the plane-wave approximation with amplitudes and phases calculated by Mc Kale and al. (7). The $\sigma^{2}$ Debye-Waller factor and $\Gamma$ whole state width were calibrated from crystalline reference compounds : $\alpha \mathrm{GeS}_{2}$ ( quasi regular tetrahedral sulfide germanium with $\mathrm{R}_{\mathrm{Ge}-\mathrm{S}}=2.22 \AA$ ) and the $\mathrm{La}_{6} \mathrm{Ga}_{2} \mathrm{Mn}_{2} \mathrm{~S}_{14}$ with a slightly distorded $\mathrm{GaS} 4$ tetrahedral surrounding : 
( $3 \mathrm{RGa}-\mathrm{S}=2.28 \AA$ and $1 \mathrm{RGa}-\mathrm{S}=2.23 \AA$ ). The simple $\mathrm{Ga}_{2} \mathrm{~S}_{3}$ binary compound presents a too wide distribution of $\mathrm{Ga}-\mathrm{S}$ distances to be used as a reference. During the fitting procedures in the first steps we alternatively adjust $\mathrm{N}, \mathrm{R}, \Delta \mathrm{E}, \sigma^{2}$ parameters and at the final step all these parameters were authorized to vary. The $\Gamma$ value when calibrated to the reference compound was let fixed.

\section{RESULTS}

The tables 1 and 2 give the fitting results about the Ga-S and Ge-S first shells coordination.

\begin{tabular}{|c|c|c|c|}
\hline & $\mathbf{N}$ & $\sigma(\AA)$ & $\mathbf{R}(\mathbf{A})$ \\
\hline La6Ga2Mn2S14. $^{\prime}$ Sample 1 $_{\text {Samp }}$ & 4 & 0.09 & 2.28 \\
\hline Sample & 4.08 & 0.1 & 2.28 \\
\hline Sample 3 & 4.10 & 0.09 & 2.28 \\
\hline
\end{tabular}

TABLE 1 : Fits results concerning the $S$ shell around $G a$ atoms, in $\mathrm{Ga}_{2} \mathrm{~S}_{3}-\mathrm{GeS}_{2}$ glasses at the room temperature.

\begin{tabular}{|c|c|c|c|}
\hline & N1 & $\sigma(\AA)$ & $\mathbf{R 1}_{1}(\mathbf{A})$ \\
\hline$\alpha \mathrm{GeS} 2$. & 4 & 0.07 & 2.22 \\
\hline Sample 1 & 3.96 & 0.07 & 2.22 \\
\hline Sample 2 & 3.95 & 0.07 & 2.22 \\
\hline Sample 3 & 3.95 & 0.08 & 2.22 \\
\hline
\end{tabular}

TABLE 2 : Fits results concerning the $S$ shell around Ge atoms, in $\mathrm{Ga}_{2} \mathrm{~S}_{3}-\mathrm{GeS}_{2}$ glasses at the room temperature.

For all these fittings the residue value was near $2.10^{-2}$. We did not observe significant differences when we studied low temperature spectra except an expected decreasing $\sigma^{2}$ value. However these low temperature measurements revealed a second shell around the Ge atoms which is quite interesting and which permits to approach medium range order informations. The figure 1 shows the pseudo radial distribution function around the Ge $\mathrm{K}$ edge obtained by Fourier transform of the normalized signal EXAFS.

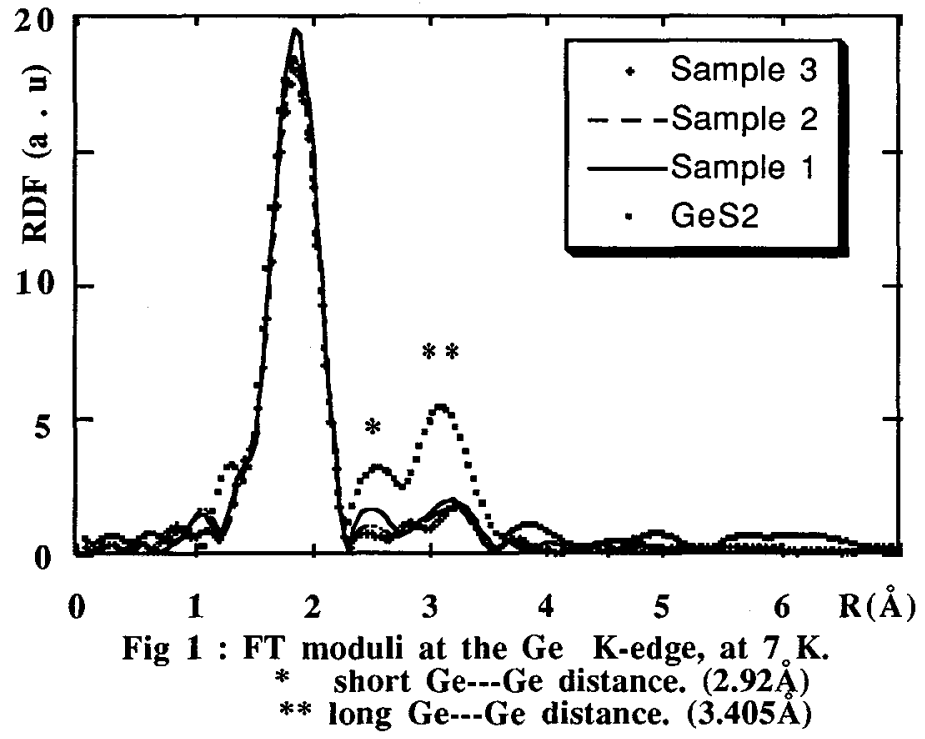


In the range from $2.3 \AA$ to $3.5 \AA$ the second and third peaks observed in the glassy samples correspond to those observed in the crystalline $\alpha \mathrm{GeS}_{2}$ and of which origine is known.These peaks are due to two kinds of Ge---Ge interactions: a shorter distance $(2.92 \AA)$ related to edge sharing tetrahedra and a longer distance more complex with value of $3.405 \AA$ related to corner sharing tetrahedra. This behaviour has been previously described by Armand and al.(8) relatively to the Ge-S glasses. Some attempts to fit these second and third shells on the crystalline reference compound (figure 2) and glass sample 2 (figure 3 ) give the following results: (table3).

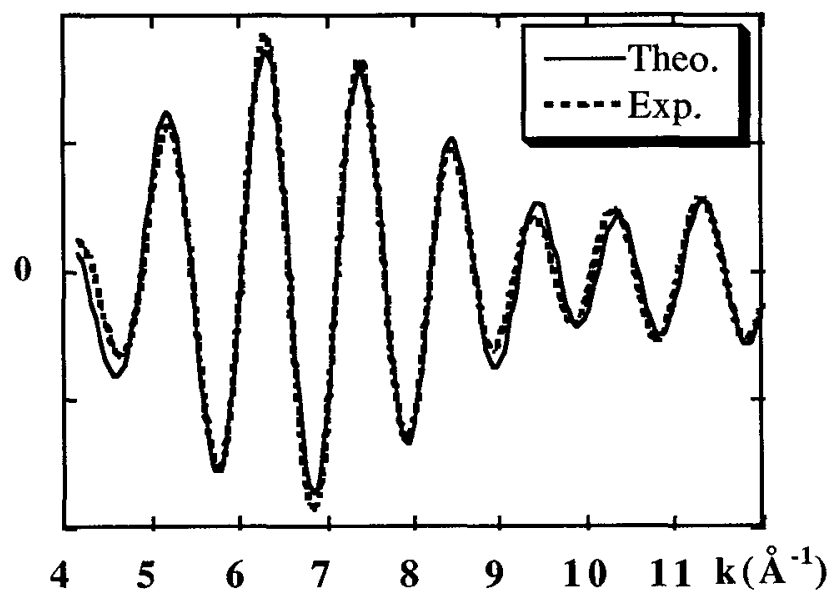

Fig 2 : Fit of the double peak corresponding to the short and long Ge---Ge distances in GeS2.

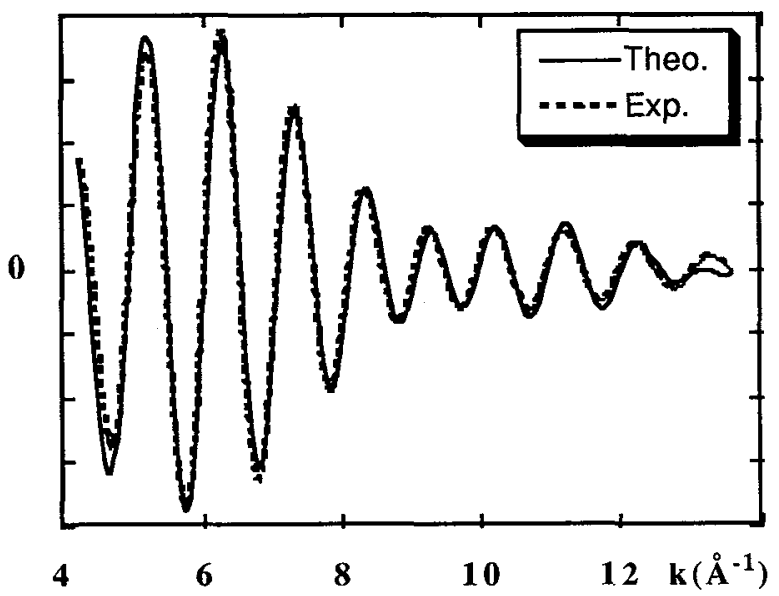

Fig 3 : Fit of the double peak corresponding to the short and long Ge-.-Ge distances in sample 2. 


\begin{tabular}{|c|c|c|c|c|c|c|}
\hline & $\mathrm{N}_{2}$ & $\sigma(\AA)$ & $\mathrm{R}_{2}(\AA)$ & $\mathrm{N}_{3}$ & $\sigma(\AA)$ & $\mathrm{R} 3(\AA)$ \\
\hline$\alpha \mathrm{GeS}_{2 .}$ & 1 & 0.08 & 2.92 & 3 & 0.07 & 3.405 \\
\hline Sample 1 & 0.57 & 0.09 & 2.95 & 3.2 & 0.10 & 3.43 \\
\hline Sample 2 & 0.39 & 0.09 & 2.97 & 3.02 & 0.11 & 3.42 \\
\hline
\end{tabular}

TABLE 3 : Fits results concerning the short and long $\mathrm{Ge}---\mathrm{Ge}$ distances in $\mathrm{Ga}_{2} \mathrm{~S}_{3}-\mathrm{GeS}_{2}$ glasses. (At the Ge K-edge and low temperature)

The more complex form of these peaks concerning the sample 3 with lowest concentration of germanium prevents us to fit this glassy composition. We conclude that in the $\mathrm{Ga}-\mathrm{Ge}-\mathrm{S}$ glasses, the germanium atoms keep the memory of the structural arrangement of the crystalline form $\alpha \mathrm{GeS}_{2}$ up to $4 \AA$. When we compare the $\sigma$ values related to the structural disorder which is the prevalent part concerning these very low temperature experiments we observe that this parameter is higher for the third shell than for the second one. That means that the corner sharing tetrahedra are more softly bounded than the edge sharing tetrahedra are, and that they are sensitive to addition of gallium atoms.

\section{DISCUSSION}

EXAFS Ga K edge analysis confirms the existence of strong GaS4 units, but does not inform about the connection between these units. By analysing Ge $\mathrm{K}$ edge spectra we conclude to a tendency of clustering to GeS4 units, some gallium atoms substituting germanium atoms inside the corner sharing tetrahedra and so distorting them. One question remains of the impossibility to evidence $\mathrm{Ga}---\mathrm{Ge}$ interactions may be due to the quite identity of there backscattering amplitude functions. However we may advance that the $\mathrm{GaS} 4$ tetrahedra do not form clusters and that may be an explanation of the impossibility to synthetize glassy Ga-S binary alloys.

Our results are not in agreement with models proposed by Ivanova (4) concerning the ( $\left.\mathrm{GeS}_{2}\right) 100-\mathrm{x}$ $\mathrm{Gax}_{\mathrm{x}}$ glasses studied by vibrational spectroscopy, neutron scattering and X-ray diffaction. These models do not respect $\mathrm{GaS} 4$ tetrahedra which are well described by our EXAFS measurements and do not propose mixt edge and corner sharing GeS4 tetrahedra.

Moreover our results bring structural informations which may be applied to the Ga-Ge-Se system , studied by Giridhar and al. (9), where selenium is in place of sulfur : in such glasses the gallium atoms probably present a four coordination and do not obey to the 8-N rule as we have observed in the $\mathrm{Ga}-\mathrm{Ge}-\mathrm{S}$ system here investigated.

\section{REFERENCES}

(1) Loireau-Lozac'h A.M. ,Thèse d'Etat, Paris, (1977)

(2) Auzel F., Michel J.C., Flahaut J.,Loireau-Lozac'h A.M., and Guittard M., C. R. Acad. Sci. Paris 291

(1980) 21-24.

(3) Bénazeth S., Tuilier M.H., Loireau-Lozac'h A.M., Dexpert H., Lagarde P., and Flahaut J., J. Non-

Cryst. Solids 110 (1989) 89-100.

(4) Ivanova Z.G., J. Molecular Structure 245 (1991) 335-340.

(5) Chbani N., Cai X., Loireau-Lozac'h A.M. and Guittard M., Mat. Res. Bull. 27 (1992) 1355-1361.

(6) TEO B.K.,Basic principles and data analysis ( Springerverlag, New York, 1986).

(7) Mc Kale A.G., Veal B.W., Paulikas A.P., Chan S.K., and Knapp S., J. Am. Chem. Soc., 110 (1988) 3763.

(8) Armand P., Ibanez A., Dexpert H. and Philippot E., J. Non-Cryst. Solids 139 (1992) 137-145.

(9) Giridhar A. and Mahadevan S., J. Non-Cryst. Solids 126 (1990) 161-169. 